\title{
Erratum to: Gastric MALT Lymphoma and Grade II Obesity: Gastric Bypass Surgery as a Therapeutic Option
}

Ricardo Helman • Priscila Pereira dos Santos Teixeira • Carlos José Lazzarini Mendes • Thomas Szegö •

Nelson Hamerschlak

Published online: 6 May 2010

(C) Springer Science+Business Media, LLC 2010

Erratum to: OBES SURG

DOI 10.1007/s11695-010-0122-2

In the original publication, the last author's surname is misspelled. It should read Nelson Hamerschlak.

The online version of the original article can be found at http://dx.doi. org/10.1007/s11695-010-0122-2.

R. Helman • P. P. dos Santos Teixeira • C. J. L. Mendes •

T. Szegö $\cdot$ N. Hamerschlak

Hematology and Bone Marrow Transplantation Department, and Bariatric Surgery Department, Albert Einstein Hospital,

São Paulo, Brazil

N. Hamerschlak $(\triangle)$

Centro de Pesquisa Clínica,

Instituto Israelita de Ensino e Pesquisa Albert Einstein,

Av. Albert Einstein, 627/520,

CEP 05256-900 São Paulo, São Paulo, Brazil

e-mail: hamer@einstein.br 